\title{
Papers
}

\section{Self reported health of people in an area contaminated by chromium waste: interview study}

\author{
Peter McCarron, Ian Harvey, Robert Brogan, Tim J Peters
}

\begin{abstract}
Objectives To compare the self reported health of a group of individuals living in an area contaminated by chromium (chromium group) with a group living in an uncontaminated area (control group), and to assess the effects of perception of risk from exposure to chromium on health.

Design Cross sectional study using the SF-36 validated quality of life questionnaire. Further questions were added to examine the relations between perceptions about living on or near land contaminated with chromium and the effects on self reported health.

Setting An area contaminated with chromium (Cambuslang, Carmyle, and Rutherglen) and a control area (Barrmulloch and Pollok).

Participants Residents of an area containing chromium landfill and residents of an uncontaminated control area.

Main outcome measures Scores on SF-36.

Results Little difference was found in health scores between the two groups, and only for general health was there a significantly higher score in the chromium group. Health scores for the chromium group were significantly worse across all dimensions for those who believed that chromium adversely affected health. Most of the chromium group (68\%) would prefer money to be spent on improving amenities rather than on chromium remediation.

Conclusions Similar self reported health among residents of the chromium and control groups indicates that there is no evidence of harm to health from exposure to chromium in this setting. Noticeably lower scores in participants who believed chromium to be harmful to health point to the potential importance of perception and possible anxiety. Given the overall greater desire for better amenities rather than remedial action, policy makers and planners should discuss with residents how best to spend resources before instigating expensive cleaning up programmes.
\end{abstract}

\section{Introduction}

Chromium waste was deposited as landfill in the Cambuslang, Carmyle, and Rutherglen area of Glasgow from 1820 to $1968 .{ }^{1}$ In 1991 six sites in the area-identified as potentially hazardous to health- were cordoned off, and in 1992 there was concern that several conditions, including leukaemia and kidney tumours, had been caused by the chromium waste, up to $20 \%$ of which is in the more toxic hexavalent form.

Chromium, the 21st most abundant element in the earth's crust, exists in three states: chromium(0), chromium(III), and chromium(VI). ${ }^{2}$ Chromium(III), an essential metabolic trace nutrient, ${ }^{3}$ is noticeably less toxic than chromium(VI), which can cause perforation of the nasal septum, ${ }^{3}$ lung cancer, ${ }^{4}$ and skin ulceration. ${ }^{5}$ Occupational studies, including those from the United Kingdom and the United States, have reported increased risks of illness in chromate workers, which declined after measures were taken to reduce exposure to chromium. ${ }^{6-8}$ Two reviews concluded that there is sufficient evidence for the carcinogenicity of chromium in chromate workers. ${ }^{4}$ In contrast, community studies have largely been negative. In New Jersey, United States, where chromium has been extensively used as landfill, no evidence of excess lung cancer or other clinical effects was found in residents. ${ }^{10} 11$

Studies to investigate the health concerns of Glasgow residents were also negative, reporting no increased risk of congenital abnormalities, ${ }^{12}$ lung cancer, ${ }^{13}$ or a range of other diseases ${ }^{14}$ from living on contaminated land compared with living elsewhere in Glasgow. Indeed the incidence of leukaemia actually rose with increasing distance from the main area of contamination. ${ }^{15}$

Despite these negative findings and the health reassurances issued to the residents, anxieties persisted, partly due to a perceived lack of impartiality of these studies (personal communication). In light of this continuing concern, and as quality of life issues are underresearched in such settings, the Greater Glasgow Health Board undertook to examine the perceived health of residents in areas of chromium landfill. We report the findings of this study.

\section{Methods}

A cross sectional survey was performed in a chromium contaminated area and in an uncontaminated control area about $10 \mathrm{~km}$ away. The control area was selected on the basis of its broad similarity to the contaminated area in terms of distribution of age, gender, and Carstairs deprivation categories of the residents. ${ }^{16}$ Individuals aged 16-74 years were surveyed.

\section{Department of Social Medicine, University of Bristol, Bristol BS8 2PR \\ Peter McCarron lecturer in epidemiology and public health medicine Tim J Peters reader in medical statistics \\ School of Health, Policy and Practice, University of East Anglia, Norwich R4 7TJ \\ Ian Harvey professor of epidemiology and public health \\ Greater Glasgow Health Board, PO Box 15329, Glasgow G3 8YZ Robert Brogan consultant in public health medicine \\ Correspondence to: P McCarron P.McCarron@ bristol.ac.uk}

BMJ 2000;320:11-5 
Table 1 Characteristics of chromium and control groups. Values are numbers (percentages) unless stated otherwise

\begin{tabular}{lccc} 
& $\begin{array}{c}\text { Chromium } \\
\text { group }(\mathbf{n = 3 9 8})\end{array}$ & $\begin{array}{c}\text { Control group } \\
(\mathbf{n}=\mathbf{4 0 1})\end{array}$ & P value \\
\hline Men & $150(38)$ & $137(34)$ & \multirow{2}{*}{0.30} \\
\cline { 1 - 3 } Women & $247(62)$ & $263(66)$ & \\
\hline Age (years): & & & \\
\hline $16-24$ & $11(3)$ & $24(6)$ & \multirow{2}{*}{0.01} \\
\hline $25-34$ & $39(10)$ & $52(13)$ & \\
\hline $35-44$ & $44(11)$ & $54(14)$ & \\
\hline $45-54$ & $55(14)$ & $60(15)$ & \\
\hline $55-64$ & $75(19)$ & $85(21)$ & \\
\hline$\geqslant 65$ & $173(44)$ & $125(31)$ & \\
\hline
\end{tabular}

\section{Multistage sampling}

After piloting, 400 houses from each area were visited by trained interviewers using a multistage sampling procedure. Areas to survey were selected, and systematic sampling of every twentieth house was carried out. The person answering the door (if aged 16-74 years) was interviewed. If this person refused or there was no reply the interviewer moved on to the next eligible house, continuing in this way until the target number of questionnaires was completed. Only one person per house was interviewed. All interviews were carried out between 9 am and $5 \mathrm{pm}$ and were completed in five days.

\section{SF-36 health questionnaire}

The SF-36 was used to measure self reported health. This comprises eight dimensions: vitality, general health, bodily pain, physical and social functioning, mental health, and role limitations due to physical and to emotional problems. After completion of the SF-36 all participants were asked about the difficulties they anticipated in moving from the area in which they lived, should they wish to do so. Additionally, residents of the contaminated area were asked whether they would attribute any such difficulties to the contamination, whether they believed that chromium was harmful to health, and how money allocated to the area should be spent. Age, gender, and housing tenure of the participants were recorded.

Statistical analysis and sample size

Means for each dimension were calculated for both groups and compared using unpaired $t$ tests, after con- sidering the distribution of the data. Multivariable regression analyses were then carried out to determine whether there were differences in SF-36 scores between the two groups after controlling for potential sociodemographic confounders. Similar analyses were then performed for the chromium group alone to examine further the effects of perceptions about harm from chromium and how money allocated should be spent.

Using published standard deviations for the SF-36 ${ }^{17}$ a sample size of 800 (400 in each group) was chosen. This conferred a power of $80 \%$ with a two tailed significance level of $5 \%$ to detect a difference in health score of five points on the 100 point scale, which is considered to be clinically significant. ${ }^{18}$

\section{Results}

After individuals who were not aged 16 -74 years were excluded, the overall response rate was $78 \%$. Table 1 shows the age and sex of the two groups. There was a significant difference in age between the two groups, with the chromium group being older. This was adjusted for in later analyses.

\section{Potential predictor variables}

In univariable analyses of the two groups combined there is significant heterogeneity across age groups for all dimensions except role emotional, with health tending to decline with age (data not shown). Gender is only significantly associated with mental health and vitality, women showing poorer scores (data not shown). Table 2 shows the associations between each of three potential predictor variables and the eight dimensions of the SF-36. Owner occupiers had the best perceived health and those in rented accommodation generally the worst. Owner occupiers who believed that there would be a definite problem selling their house had lower health scores than those who believed that this was less likely and this was statistically significant for the dimensions of general, social and mental health, and role emotional.

Comparison of chromium and control groups

Table 3 shows the difference between the two groups for each dimension of the SF-36. In the univariable

Table 2 Associations between the three potential predictors of health and eight dimensions of the SF-36 in the chromium and control groups combined (all scores range from 0 to 100)

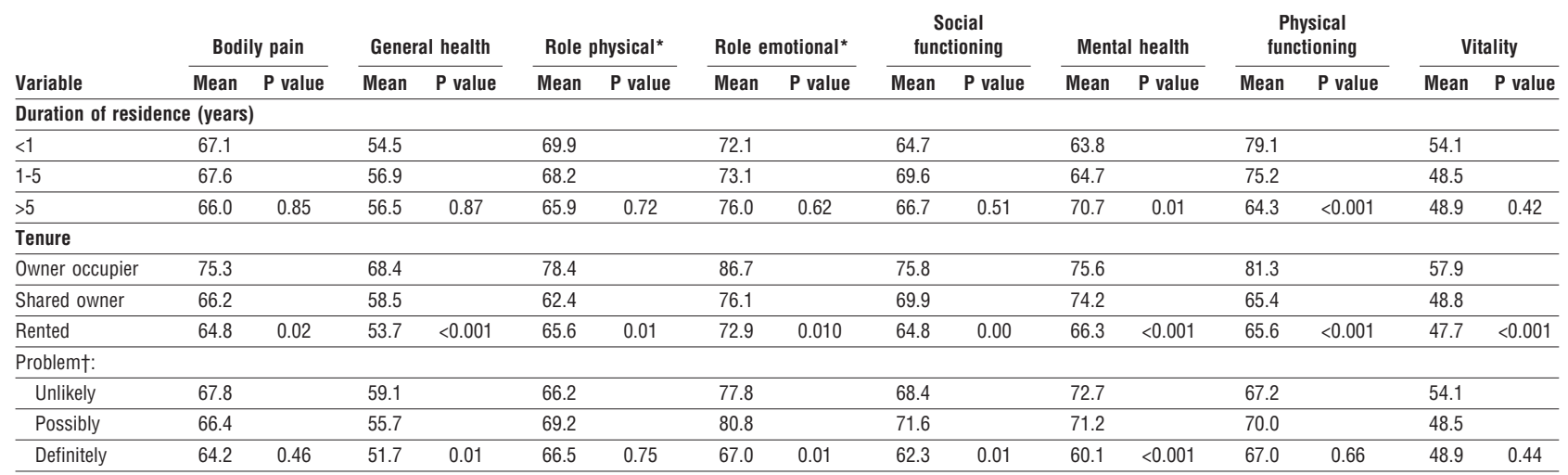

${ }^{*}$ Role limitations due to physical or emotional problems.

†Defined as whether respondents believe they will have problems selling their house. 
Table 3 Comparison of SF-36 scores between chromium and control groups. Values are means unless stated otherwise

\begin{tabular}{|c|c|c|c|c|c|c|c|c|}
\hline \multirow[b]{2}{*}{ SF-36 dimension } & \multicolumn{4}{|c|}{ Unadjusted } & \multicolumn{2}{|c|}{ Adjusted* } & \multicolumn{2}{|c|}{ Adjusted† } \\
\hline & $\begin{array}{c}\text { Chromium group } \\
(\mathrm{n}=395-398 \ddagger)\end{array}$ & $\begin{array}{c}\text { Control group } \\
(\mathrm{n}=400)\end{array}$ & $\begin{array}{c}\text { Difference } \\
(95 \% \mathrm{Cl})\end{array}$ & $P$ value & $\begin{array}{l}\text { Difference } \\
(95 \% \mathrm{CI})\end{array}$ & $P$ value & $\begin{array}{c}\text { Difference } \\
(95 \% \mathrm{Cl})\end{array}$ & $P$ value \\
\hline Bodily pain & 63.9 & 68.8 & $-4.9(-9.7$ to -0.2$)$ & 0.04 & $-3.6(-8.3$ to 1.1$)$ & 0.14 & $-3.9(-8.9$ to 1.0$)$ & 0.12 \\
\hline Role physical§ & 68.1 & 65.1 & 3.0 (-2.9 to 8.9$)$ & 0.31 & $4.7(-1.2$ to 10.6$)$ & 0.12 & $3.9(-2.3$ to 10.1$)$ & 0.21 \\
\hline Role emotional§ & 75.6 & 74.8 & 0.9 (-4.8 to 6.6$)$ & 0.76 & $1.2(-4.6$ to 6.9$)$ & 0.69 & $1.1(-4.9$ to 7.1$)$ & 0.72 \\
\hline Social functioning & 67.6 & 66.7 & $1.0(-3.4$ to 5.3$)$ & 0.67 & $1.7(-2.7$ to 6.1$)$ & 0.45 & $2.2(-2.3$ to 6.8$)$ & 0.34 \\
\hline Physical functioning & 64.2 & 70.7 & $-6.5(-11.1$ to -2.0$)$ & $<0.01$ & $-3.4(-7.6$ to 0.9$)$ & 0.12 & $-4.0(-8.4$ to 0.5$)$ & 0.08 \\
\hline Vitality & 48.6 & 49.7 & $-1.1(-5.0$ to 2.8$)$ & 0.58 & -0.6 ( -4.5 to 3.3$)$ & 0.75 & $-0.5(-4.5$ to 3.6$)$ & 0.83 \\
\hline
\end{tabular}

${ }^{*}$ Adjusted for age group and sex.

†Adjusted for sex, age group, housing tenure, years lived at current address, and perceived difficulty in selling house

$\ddagger$ Number depended on whether relevant question was asked.

$\S$ Role limitations due to physical or emotional problems.

analysis there are small but statistically significant differences between the two groups for the dimensions of bodily pain, general and physical health, and vitality in the direction of better health in the control group. After adjustment for age and gender there was little change in the differences between the two groups but none of the differences was now significant. Further adjustment for the potential confounding of the other three factors measured in both groups resulted in little change, although for general health there was a statistically significant difference-again in the direction of better health in the control group.

\section{Perception of health risk from chromium}

Table 4 shows the scores on the SF-36 dimensions in the chromium group alone for those who believed chromium to be harmful and those who thought it was not harmful. Overall, 25\% (98/398) of the chromium group believed that chromium was harmful. In the unadjusted analyses there were large and highly statistically significant differences in all dimensions of the SF-36, with those who believed chromium to be harmful having noticeably worse scores than either those who did not believe it was harmful or those (18/398) who did not know (data not shown). These differences persisted and remained highly significant after adjustment for the same sociodemographic variables as above. Overall, individuals who perceived chromium to be harmful to health scored on average at least 16 points lower on the relevant SF-36 dimensions than did those who thought otherwise.

\section{Views on resource allocation}

Participants in the chromium group were also asked how they would like money to be used if it were allocated to their area. Less than one third (121/383) favoured chromium remediation-removal or burial of the chromium waste-the remainder preferring expenditure on local amenities, housing, education, or employment. There are minor non-significant differences in adjusted scores between these two groups, ranging from $-1.4(95 \%$ confidence interval -10.4 to 7.6) to 2.6 ( -3.0 to 8.3 ), and the direction of better health is heterogeneous. Adjustment for sociodemographic variables did not affect these results.

\section{Discussion}

In this study, multivariable analyses showed that after adjustment for a range of mainly sociodemographic variables there was little difference in scores on the SF-36 between people living on or near land containing chromium and those living elsewhere. Only for general health was the lower score among the chromium group statistically significant, but this difference was not clinically significant. ${ }^{18}$ In the chromium group, perceived health was worse in those who believed that chromium is harmful to health. Two thirds preferred money to be spent in other areas governing quality of life rather than on chromium remediation.

\section{Study limitations}

The drawbacks of this study include its cross sectional nature, which precludes verification of the direction of the associations. It is possible, although we believe unlikely, that chromium induced ill health causes individuals to correctly identify chromium as a health problem. Lack of objective validation of health status from medical records, the possibility of bias owing to awareness of the key hypotheses among participants,

Table 4 Comparison of SF-36 scores among residents of chromium contaminated land according to perception of whether chromium contaminated land is harmful to health. Values are means unless stated otherwise

\begin{tabular}{|c|c|c|c|c|c|c|}
\hline \multirow[b]{2}{*}{ SF-36 dimension } & \multicolumn{4}{|c|}{ Unadjusted } & \multicolumn{2}{|c|}{ Adjusted* } \\
\hline & Harmful & Not harmful & Difference $(95 \% \mathrm{CI})$ & $P$ value & Difference $(95 \% \mathrm{CI})$ & $P$ value \\
\hline Bodily pain & 51.9 & 67.7 & $-15.8(-23.6$ to -7.9$)$ & $<0.001$ & $-17.2(-25.2$ to -9.2$)$ & $<0.001$ \\
\hline General health & 42.6 & 59.1 & $-16.5(-22.4$ to -10.5$)$ & $<0.001$ & $-17.3(-23.3$ to -11.4$)$ & $<0.001$ \\
\hline Role physical† & 55.4 & 73.0 & $-17.6(-27.2$ to -8.1$)$ & $<0.001$ & $-22.6(-32.5$ to -12.7$)$ & $<0.001$ \\
\hline Role emotional† & 59.9 & 82.7 & $-22.8(-31.8$ to -13.9$)$ & $<0.001$ & $-21.9(-31.3$ to -12.6$)$ & $<0.001$ \\
\hline Social functioning & 55.5 & 72.6 & $-17.1(-24.0$ to -10.1$)$ & $<0.001$ & $-18.0(-25.0$ to -10.9$)$ & $<0.001$ \\
\hline Mental health & 58.5 & 74.3 & $-15.8(-20.9$ to -10.6$)$ & $<0.001$ & $-15.0(-20.2$ to -9.8$)$ & $<0.001$ \\
\hline Physical functioning & 54.1 & 66.8 & $-12.7(-20.5$ to -5.0$)$ & 0.0013 & $-15.7(-23.0$ to -8.5$)$ & $<0.001$ \\
\hline Vitality & 37.0 & 53.2 & $-16.2(-22.2$ to -10.3$)$ & $<0.001$ & $-16.4(-22.5$ to -10.3$)$ & $<0.001$ \\
\hline
\end{tabular}

*Adjusted for sex, age group, housing tenure, years at address, and perceived difficulty in selling house.

†Role limitations due to physical or emotional problems. 
and the availability of only comparatively crude data on potential confounders-age groups and overall socioeconomic status of the two groups-may limit the robustness of the findings. As interviews were conducted during the day participants could have been unrepresentative in terms of employment and health status.

\section{Health risks}

Although chromium has known toxic effects, our findings are consistent with those from several previous negative investigations of the role of chromium on health in this population. ${ }^{12-15}$ A more recent study on the health effects of living near to landfill sites in Europe showed an increased risk of congenital birth defects (odds ratio 1.63, 1.09 to 2.44 ) in Glasgow. ${ }^{19}$ In this study, however, it is likely that contamination of landfill included a wide range of toxins.

\section{Risk perception and health}

Despite the overall negative findings, the lower scores in participants who believe that chromium is harmful raises the possibility that knowledge of the history of land use may reduce generic quality of life in the absence of any documented adverse health effects. This points to the importance of perception in mediating reported health status. Other studies have raised similar issues. In one such study respondent "personality variables," such as hypochondriasis, opinions about waste disposal, and environmental worry were associated with higher prevalences of physical and psychological symptoms. ${ }^{2021}$ Similarly, the Camelford incident, where the water supply in North Cornwall was contaminated by aluminium sulphate, suggested that the perception of normal and benign somatic symptoms may have been heightened by litigation, community action, self appointed experts, consumer opinion polls, media attention, and accusations of a conspiracy. ${ }^{22}$ The need for a prompt response, taking into account the importance of social and cultural factors, was underlined. ${ }^{22}$ Such factors include the nature of the public perception of risk. Risk is a social construct, and it is important in evaluating the threat from environmental hazards to introduce more public participation into both risk assessment and risk decision making. ${ }^{23}$ This makes the decision making process more democratic, improving the relevance and quality of scientific investigation and enhancing the legitimacy and public acceptance of the resulting decisions. In the current setting, a perceived lack of impartiality of investigations into chromium ( $G$ Watt, personal communication) highlights the importance of early public participation when evaluating health risks of environmental waste. An irony that underlines the complexity of this situation is that most of the chromium group preferred money to be spent in other areas governing quality of life rather than on chromium remediation.

\section{Conclusions}

Landfill sites are a potentially important cause of environmental pollution and ill health and studies are needed to determine the size and nature of such potential risks. Even when detrimental health effects can be ruled out it is vital to determine whether there

\section{What is already known on this topic}

Chromium is known to cause physical health problems such as lung cancer, perforation of the nasal septum, and skin ulceration. Most reports of health effects have been in occupational settings

Epidemiological studies have generally been negative, including three studies carried out in a chromium contaminated area of Glasgow. These studies have, however, not been considered to be impartial by residents. Moreover, little research has been carried out into the self reported health of such residents

\section{What this paper adds}

Potential exposure to chromium is not associated with poorer self reported health

In individuals who perceive chromium to be harmful to health, however, health scores were lower than those in the rest of the population. Concurrently there was a desire for money to be used to improve amenities in the area in preference to chromium remediation

Early public participation is important when evaluating the health risks from environmental waste

are other factors that may be responsible for grievances among exposed populations and what measures can be taken to combat these. Although we are unable to completely discount the possibility of poorer health in the chromium group, our findings, in combination with those of earlier studies, ${ }^{12-15}$ are reassuring and important and reinforce the need for early dialogue with communities to debate the real nature of the problems.

We thank Dr John Womerseley and Mr Tom Sinclair of Greater Glasgow Health Board for assistance in choosing an appropriate control area.

Contributors: PMcC contributed to the design, planning, and conduct of the study and participated in data analysis and writing of the paper. He will act as guarantor for the paper. IH participated in data analysis and writing of the paper. RB contributed to the design, planning, and conduct of the study and made critical comments on the first draft. TJP helped with statistical analyses and contributed critically to the final draft of the paper.

Funding: Greater Glasgow Health Board.

Competing interests: None declared.

1 Public analyst of Strathclyde regional council. Soils from Rutherglen site investigation. Report to the director of architecture and related services (G/AR/22 to 30). Glasgow: City of Glasgow District Council, 1989.

2 Barnhart J. Occurrences, uses, and properties of chromium. Regul Toxicol Pharmacol 1997;26:3-7S

3 Langard S, Norseth T. Chromium. In: Handbook on the toxicology of metals. Oxford: Elsevier Science, 1975.

4 Hughes K, Meek ME, Seed LJ, Shedden J. Chromium and its compounds-evaluation of risks to health from environmental exposure in Canada. J Environ Sci Health B 1994;12:237-55.

5 Bidstrup PL, Wagg R. Chromium alloys and compounds. In: Encyclopaedia of occupational health and safety. Geneva: International Labour Office, 1983.

6 Bidstrup PL. Carcinoma of the lung in chromate workers. Br J Ind Med 1951;8:302-5.

7 Bidstrup PL, Case RAM. Carcinoma in the lung in workmen in the bichromates-producing industry in Great Britain. $\mathrm{Br} J$ Ind Med 1956;13:260-4.

8 Pastides H, Austin R, Lemeshow S, Klar J, Mundt KA. A retrospectivecohort study of occupational exposure to hexavalent chromium. Am J Ind Med 1994;25:663-75. 
9 International Agency for Research on Cancer. IARC monographs on the evaluation of carcinogenic risks to humans: chromium, nickel and welding. Lyons: IARC, 1990;38:49-256.

10 Fagliano JA, Savrin J, Udasin I, Gochfeld M. Community exposure and medical screening near chromium waste sites in New Jersey. Regul Toxicol Pharmacol 1997;26:13-22S.

11 Anderson RA, Colton T, Doull J, Marks JG, Smith RG, Bruce GM, et al. Designing a biological monitoring program to assess community

12 Eizaguirre D, Watt G, Hole DJ. Prevalence of congenital anomalies

13 Department of Public Health, Greater Glasgow Health Board. Assessment gow: GGHB, 1991.

14 Eizaguirre D. Use of routine health data in the assessment of an environmental hazard to health. Report to Greater Glasgow Health Board. Glasgow: University of Glasgow, 1993

15 Eizaguirre D. Industrial toxic waste and health: a practical case study. $\mathrm{PhD}$ thesis. Glasgow: University of Glasgow, 1996. exposure to chromium-conclusions of an expert panel.J Toxicol Environ Health 1993;40:555-83. around an area of chromium contaminated land. J Public Health Med 1999. (In press.) of the risk to human health from land contaminated by chromium waste. Glas-
16 Carstairs V, Morris G. Deprivation and health in Scotland. Aberdeen: Aberdeen University Press; 1991

17 Jenkinson C, Coulter A, Wright L. Short form 36 (SF36) health survey questionnaire: normative data for adults of working age. $B M$ 1993:306:1437-40.

18 Ware JE. SF-36 health survey: manual and interpretation guide. Boston: Health Institute, 1993. The risk of congenital anomalies near hazardous-waste land-fill sites in Europe: the EUROHAZCON study. Lancet 1998;352:423-7.

20 Roht LH, Vernon SW, Weir FW, Pier SM, Sullivan P, Reed LJ. Community exposure to hazardous waste disposal sites: assessing reporting bias. $A m$ J Epidemiol 1985;122:418-33.

21 Shusterman D, Lipscomb J, Neutra R, Satin K. Symptom prevalence and odor-worry interaction near hazardous waste sites. Environ Health Perspect 1991:94:25-30.

22 David AS, Wessely SC. The legend of Camelford: medical consequence of a water pollution accident. J Psychosom Res 1995;39:1-9.

23 Slovic P. Public perception of risk. Environ Health 1997;54:22-3.

(Accepted 16 September 1999)
19 Dolk H, Vrijheid M, Armstrong B, Abramsky L, Bianchi F, Garne E, et al.

\section{Effect of socioeconomic deprivation on waiting time for cardiac surgery: retrospective cohort study}

\author{
Jill P Pell, Alastair C H Pell, John Norrie, Ian Ford, Stuart M Cobbe
}

\author{
Abstract \\ Objective To determine whether the priority given to \\ patients referred for cardiac surgery is associated with \\ socioeconomic status. \\ Design Retrospective study with multivariate logistic \\ regression analysis of the association between \\ deprivation and classification of urgency with \\ allowance for age, sex, and type of operation. \\ Multivariate linear regression analysis was used to \\ determine association between deprivation and \\ waiting time within each category of urgency, with \\ allowance for age, sex, and type of operation. \\ Setting NHS waiting lists in Scotland. \\ Participants 26642 patients waiting for cardiac \\ surgery, 1 January 1986 to 31 December 1997. \\ Main outcome measures Deprivation as measured by \\ Carstairs deprivation category. Time spent on NHS \\ waiting list. \\ Results Patients who were most deprived tended to \\ be younger and were more likely to be female. \\ Patients in deprivation categories 6 and 7 (most \\ deprived) waited about three weeks longer for surgery \\ than those in category 1 (mean difference 24 days, \\ $95 \%$ confidence interval 15 to 32 ). Deprived patients \\ had an odds ratio of 0.5 (0.46 to 0.61$)$ for having their \\ operations classified as urgent compared with the \\ least deprived, after allowance for age, sex, and type of \\ operation. When urgent and routine cases were \\ considered separately, there was no significant \\ difference in waiting times between the most and least \\ deprived categories. \\ Conclusions Socioeconomically deprived patients are \\ thought to be more likely to develop coronary heart \\ disease but are less likely to be investigated and \\ offered surgery once it has developed. Such patients \\ may be further disadvantaged by having to wait \\ longer for surgery because of being given lower \\ priority.
}

\section{Introduction}

Socioeconomic deprivation is associated with both prevalence of and mortality from coronary heart disease. $^{1-3}$ Social class differences in mortality from coronary heart disease have widened over the past three decades. ${ }^{4}$ Despite being at greater risk of developing coronary heart disease and dying from it, patients in lower socioeconomic groups are less likely to be investigated once the disease develops ${ }^{5-10}$ and are less likely to be referred for cardiac surgery thereafter. ${ }^{5-12}$

We studied whether socioeconomic inequalities also exist in the priority given to patients on the waiting list for cardiac surgery.

\section{Methods}

In Scotland information is routinely collected on every patient who is added to the waiting list for cardiac surgery by using the Scottish Morbidity Record 20 (SMR20) system. The Information and Statistics Division of the Common Services Agency in Edinburgh collates these data. The division provided SMR20 data on all patients on the cardiac surgery waiting list from 1 January 1986 to 31 December 1997. The information included age, sex, urgency, type of operation, dates of entry on to and exit from the waiting list, date of surgery, and postcode. The postcodes were used to derive Carstairs socioeconomic deprivation categories. ${ }^{13}$ These range from 1 to 7 and are based on 1991 census data on car ownership, unemployment, overcrowding, and social class within postcodes. Category 1 denotes the least deprived areas and 7 the most deprived.

Multivariate logistic regression analysis was used to determine whether the deprivation category was associated with surgery being classified as urgent, after allowance for age, sex, and type of operation. Multivariate linear regression analysis was used to determine

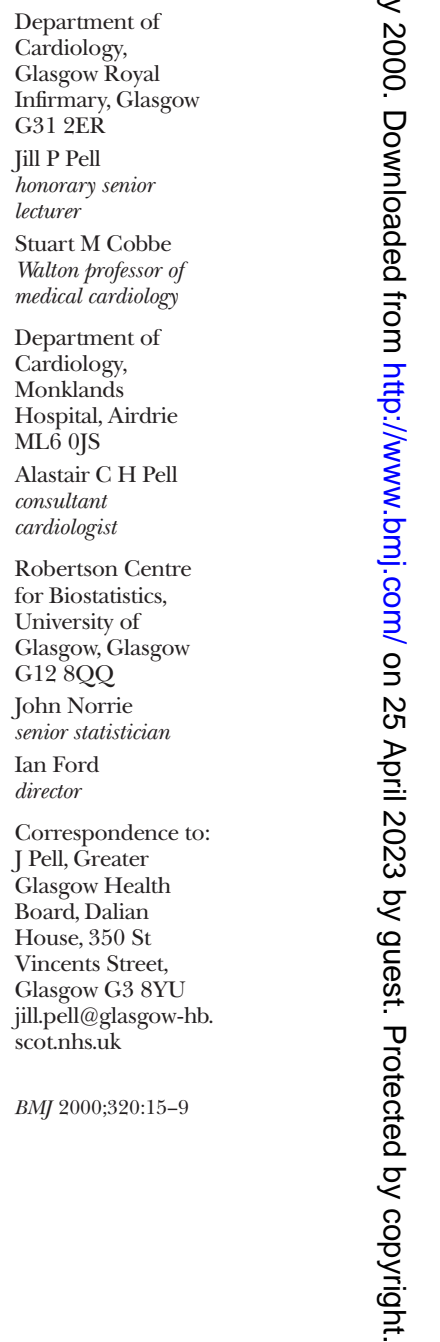

